\title{
Substituindo o uso de bordaduras laterais por repetições em experimentos com milho
}

\author{
Replacing lateral borders by replications in corn experiments
}

\author{
Sérgio José Ribeiro de Oliveira ${ }^{1}$ Sandra Feijón ${ }^{2}$ Lindolfo Storck $^{3}$ Sidinei José Lopes ${ }^{4}$ \\ Luiz Fernando Dias Martini ${ }^{5}$ Henrique Perin Damo ${ }^{5}$
}

\section{RESUMO}

O uso de bordaduras, aliado ao número adequado de repetições para definir um plano experimental, tem sido pouco estudado. Dois híbridos de milho foram avaliados com o objetivo de estimar o número de repetições necessários, substituindo-se o uso de bordaduras laterais por um maior número de filas por parcela. Foram utilizados oito tratamentos que proporcionaram comparar parcelas de duas, três, quatro e cinco filas, com e sem as duas bordaduras laterais, além de duas e três filas com bordadura simples. Verificou-se que não houve diferenças entre as estimativas das médias de híbridos $e$ dos diferentes tipos de parcelas e nem efeito da interação entre tipos de parcelas e híbridos. Constatou-se homogeneidade nas estimativas das variâncias entre os tipos de parcelas para os dois híbridos. Em experimentos de comparação de híbridos de milho, não é vantajoso substituir o uso de bordaduras por um número maior de repetições. No entanto, um maior número de repetições, sendo que oito repetições de parcelas de duas filas, proporcionam os planos experimentais mais precisos.

Palavras-chave: Zea mays, delineamento experimental, precisão.

\section{ABSTRACT}

Few studies were conducted so far in regard to the use of row borders and number of replications to define an experimental plan. Therefore an experiment was conducted in order to estimate the number of replications necessary to substitute greater row numbers of the plot for the use on row borders. Two corn hybrids were used and eight treatment in which plots with two, three, four and five rows with and without two lateral row borders and two and three row plots with a single border row. There was neither difference among the estimated yield average of the hybrids and the different plots and nor interaction between the plot forms and hybrids as well as homogeneity of variance estimates among the plots of the two hybrids. In hybrid corn yield experiments there is no advantage to substitute the use of row borders for greater number of replications. However, a greater number of replications such as eight replications and two row plots with no border rows, will result in more precise experimental plans.

Key words: Zea mays, experimental design, precision.

\section{INTRODUÇÃO}

A cultura do milho, no Brasil e no mundo, tem grande importância econômica e social; serve como alimento para pessoas e animais, é matéria-prima na indústria e sua demanda é crescente. Pesquisas visando melhorar a produtividade, com redução de

\footnotetext{
${ }^{1}$ Engenheiro Agrônomo, Professor Assistente do Departamento de Ciências Exatas e Tecnológicas (DCET), Universidade Estadual de Santa Cruz (UESC), Doutorando em Agronomia na Universidade Federal de Santa Maria (UFSM).

${ }^{2}$ Engenheiro Agrônomo, Doutorando em Agronomia, UFSM.

${ }^{3}$ Engenheiro Agrônomo, Doutor, Professor Titular, Departamento de Fitotecnia, UFSM, 97105-900, Santa Maria, RS, Email:storck@ccr.ufsm.br. Autor para correspondência.

${ }^{4}$ Engenheiro Agrônomo, Doutor, Professor Adjunto, Departamento de Fitotecnia, UFSM.

${ }^{5}$ Aluno do Curso de Agronomia, UFSM, Bolsista de Iniciação Científica.
} 
custos, são realizadas por órgãos públicos e privados, usando-se técnicas experimentais para identificar os melhores procedimentos de cultivo. Uma grande ênfase é dada ao melhoramento genético, cujos resultados são avaliados nos ensaios de competição de híbridos. Nestes ensaios, uma boa precisão experimental é imprescindível para a identificação de híbridos superiores.

Sabe-se que o rendimento de grãos da cultura de milho é influenciado pelas variações ambientais devido à interação entre genótipo e ambiente, como se observa nos trabalhos de análise de estabilidade (SOUZA et al., 1991; MARODIM, 1999). Essa variação ambiental é a principal causa da baixa precisão dos experimentos com milho, comparada a outras culturas (LÚCIO \& STORCK, 1999; LÚCIO et al., 1999).

São muitas as fontes conhecidas de erro experimental (STORCK et al., 2000), o qual pode ser avaliado pelas estatísticas: coeficiente de variação, diferença mínima significativa, dentre outras. $\mathrm{Na}$ cultura de milho, as causas responsáveis pela baixa precisão foram estudadas em vários trabalhos (LOPES, 1993; SILVA et al., 1994; LOPES \& STORCK, 1995; LÚCIO \& STORCK, 1999; LÚCIO et al., 1999; MARQUES, 1999; CARGNELUTTI FILHO et al., 2003). Dentre as causas de erros mais importantes, pode-se destacar a competição interparcelar, que pode ser controlada pelo uso de bordaduras. No entanto, o uso de bordaduras em áreas limitadas está diretamente relacionado ao número de repetições (STORCK et al., 2000). No caso de experimentos de comparação da produtividade de híbridos de milho, a competição interparcelar é devida, principalmente, a diferenças na arquitetura, na estatura de plantas e/ou ciclo, porque estes afetam a interceptação da radiação e a polinização (CARGNELUTTI FILHO, 2002).

Trabalhos de pesquisa visando estimar e/ ou identificar o efeito de bordadura na cultura de milho e em outras culturas, em geral, referem-se à sua relação com o número de repetições na determinação do plano experimental. No entanto, não são precisos no uso dessa relação para a definição de um plano experimental mais eficiente, por falta de dados experimentais específicos para tal fim.

O objetivo deste trabalho foi estimar o número de repetições necessárias para um experimento de competição entre dois híbridos de milho, substituindo-se as bordaduras laterais por um número maior de filas por parcela. Buscou-se, desta forma, determinar qual o tamanho de parcela, dentre as estudadas, que proporciona o melhor plano experimental.

\section{MATERIAL E MÉTODOS}

O experimento foi conduzido na área experimental do Departamento de Fitotecnia da Universidade Federal de Santa Maria, RS, no ano agrícola 2002/03, em solo da unidade de mapeamento Santa Maria (Brunizem Hidromórfico).

Oito tipos de parcelas (tratamentos), variando o número de filas da área útil e o número de filas de bordadura, foram casualizados em parcelas principais segundo o delineamento experimental inteiramente casualizado, com desbalanceamento do número de repetições, para tornar fixa a área total disponibilizada a cada tratamento, conforme apresentado na Tabela 1 . As filas de 5,0m de comprimento foram espaçadas em $0,8 \mathrm{~m}$. Nas parcelas principais, foram casualizados dois híbridos (subparcelas): híbrido simples (HS) P30F33 - Pioneer, cujo ciclo é de 77 dias e 2,10m de altura; e, híbrido duplo (HD) AGN 2012 - Agromen, cujo ciclo é de 76 dias e altura de 2,06m. O híbrido triplo (HT) AGN 3150 - Agromen, com ciclo de 77 dias e altura de 1,85m, foi utilizado como borda nos tratamentos 7 e 8

Tabela 1 - Caracterização dos tipos de subparcelas (tratamentos): número de repetições (NR) e número total de filas (NF).

\begin{tabular}{lccc}
\hline Tipo & Descrição* & NR & NF \\
\hline T1 & Duas filas & 12 & 24 \\
T2 & Três filas & 8 & 24 \\
T3 & Quatro filas - avaliação das duas filas centrais & 6 & 24 \\
T4 & Quatro filas - avaliação das quatro filas & 6 & 24 \\
T5 & Cinco filas - avaliação das três filas centrais & 5 & 5 \\
T6 & Cinco filas - avaliação das cinco filas & 8 & 25 \\
T7 & Duas filas mais uma fila de borda comum às subparcelas & 6 & 24 \\
T8 & Três filas mais uma fila de borda comum às subparcelas & 24 \\
\hline
\end{tabular}

* Filas de 5,0m espaçadas em 0,8m. 
(Tabela 1), para separar as subparcelas dos diferentes híbridos.

A semeadura foi realizada em 07/11/2002, e o desbaste em 05/12/2002. Os tratos culturais, tais como adubação, irrigação e aplicação de defensivos, foram realizados de forma que o desenvolvimento e o crescimento da cultura não fossem afetados por déficit hídrico, plantas daninhas, pragas, doenças e deficiências nutricionais. Avaliaram-se o número de espigas e o rendimento de grãos a 13\% de umidade em 24/03/2003, desprezando-se $0,5 \mathrm{~m}$ das extremidades das filas.

Para as duas variáveis, procedeu-se à análise de variância, com teste F, a fim de verificar se houve diferenças nas estimativas das médias para tipos de parcelas e híbridos e para o efeito da interação entre tipos de parcelas e híbridos. Aplicou-se o teste de Bartlett com o objetivo de verificar a homogeneidade das variâncias entre os tipos de parcelas para cada um dos híbridos. Estimou-se o número de repetições (n) necessárias para diferentes semi-amplitudes do intervalo de confiança expresso em percentagem da média (D), separadamente para cada tipo de parcela e híbrido, bem como na média de híbrido e na média geral, usando-se a expressão: $\mathrm{n}=\mathrm{t}^{2} \mathrm{CV}^{2} / \mathrm{D}^{2}$, onde t é o valor tabelado da distribuição de $\mathrm{t}$ com $5 \%$ de probabilidade de erro e GL=n-1 graus de liberdade; $\mathrm{CV}=$ coeficiente de variação expresso em percentagem da média; e, $\mathrm{D}=10,20$ e $30 \%$. O processo iterativo do cálculo de $\mathrm{n}$ é concluído quando o estimativa de n estabiliza com o GL.

\section{RESULTADOS E DISCUSSÃO}

O uso de diferentes tipos de parcelas, com variações no número de filas e de repetições, bem como no uso de bordaduras, resulta nas mesmas estimativas das médias para os dois híbridos e entre híbridos, para as variáveis rendimento de grãos e número de espigas (Tabela 2). O coeficiente de variação da subparcela da variável rendimento de grãos é classificado como muito alto (>23\%) (LÚCIO et al., 1999). Muitos outros autores, dentre os quais LOPES, (1993), LOPES \& STORCK, (1995), MARQUES, (1999) e CARGNELUTTI FILHO et al. (2003) também constataram uma baixa precisão nos experimentos com a cultura de milho. Isto permite inferir que a cultura é bastante sensível a variações ambientais.

As estimativas das médias de rendimento e do número de espigas, para os dois híbridos, em relação aos diferentes tipos de parcelas, cujas diferenças não são significativas, estão apresentadas na tabela 3. Com isso, é indiferente, quanto aos valores das estimativas, o uso de doze repetições de parcelas com duas filas ou, por exemplo, de seis repetições de parcelas com quatro filas (com ou sem uso da bordadura). Constata-se também (Tabela 3) que as variâncias associadas aos diferentes tipos de parcelas, para os dois híbridos e as duas variáveis, são homogêneas pelo teste de Bartlett (Tabela 3). Isto indica que a precisão experimental, no caso, não está relacionada às combinações do número de repetições com o número de filas por parcela (com ou sem o uso da bordadura).

De modo geral, o híbrido simples, usado neste experimento, apresentou uma variação ambiental ( $\mathrm{CV}=32,13 \%)$ não significativamente maior do que o híbrido duplo $(\mathrm{CV}=23,19 \%)$, o que não contraria os resultados encontrados por outros autores (NASPOLINI FILHO, 1975; MARTIN, 2003). No entanto, para fins de estimação por intervalo e/ ou testes de hipótese, a comparação das variâncias entre os tipos de parcelas deve ser procedida pela estimativa da variância da média $\left[\mathrm{V}_{(\mathrm{M})}\right]$ para padronizar o número de repetições. Neste caso, observam-se diferenças maiores de $V_{(M)}$ entre os tipos de parcelas.

Uma forma mais completa e mais informativa de se verificar o efeito dos tipos de parcela consiste em avaliar a estimativa do número de repetições para cada caso (Tabela 4). Quanto ao rendimento de grãos, usando-se oito parcelas do tipo T1 (duas filas) ou quatro parcelas do tipo T4 (4 filas sem borda) no híbrido simples, resulta numa mesma precisão experimental de $30 \%$ de diferença mínima significativa, num total de 16 filas por tratamento. Por outro lado, no caso do híbrido duplo, a mesma precisão é obtida com 10 filas (cinco repetições de duas filas) ou, de forma semelhante, com 12 filas (quatro repetições de três filas - uma borda e duas úteis).

O número total de filas por tratamento pode ser avaliado a partir das estimativas do número de repetições para cada tratamento utilizado (Tabela 4). Para rendimento de grãos com $\mathrm{D}=30 \%$, os experimentos podem ter suas dimensões menores com o uso dos tipos de parcela T1 e T4 para o híbrido simples e T1 e T7 para o híbrido duplo. Os piores tipos, para ambos os híbridos, foram proporcionados por T5 e T6 com o uso de cinco filas por parcela, independente do uso ou não de bordadura. Quanto ao número de espigas com $\mathrm{D}=20 \%$, os melhores tipos foram proporcionados pelas parcelas T1 e T2 para o híbrido simples e T1, T2 e T7 para o híbrido duplo. Como os piores tipos foram 
Tabela 2 - Análise de variância contendo graus de liberdade (GL) e quadrados médios para as variáveis rendimento de grãos e número de espigas de milho, média e coeficiente de variação da parcela (CVa) e da subparcela (CVb). Santa Maria, 2003.

\begin{tabular}{lccc}
\hline \multirow{2}{*}{ Causas de variação } & GL & & Quadrado médio \\
\cline { 3 - 4 } & & Rendimento de grãos $^{\text {No de espigas }}$ \\
\hline Tipos de parcela (T) & 7 & $0,964^{\mathrm{ns}}$ & $21,92^{\mathrm{ns}}$ \\
Erro (a) & 48 & 1,766 & 66,68 \\
Híbridos (H) & 1 & $0,511^{\mathrm{ns}}$ & $8,88^{\mathrm{ns}}$ \\
T vs H & 7 & $0,491^{\mathrm{ns}}$ & $12,24^{\mathrm{ns}}$ \\
Erro (b) & 48 & 1,590 & 53,92 \\
Média & --- & 4,474 t/ha & 41,606 milhares ha \\
Cva & --- & $29,7 \%$ & $19,6 \%$ \\
CVb & --- & $28,1 \%$ & $17,6 \%$ \\
\hline
\end{tabular}

+ = tipos de parcelas conforme a tabela 1; ns = não significativo.

obtidos a partir da utilização das parcelas T5 e T6 em ambos os híbridos, não é aconselhável o uso de parcelas com cinco filas, avaliando-se as três filas centrais.

A parcela T1 sempre esteve entre os melhores planos obtidos, tanto para rendimento de grãos quanto para número de espigas, em ambos os híbridos. Com exceção do número de espigas para o híbrido simples, quando se apresentou inferior ao tipo T2, e para rendimento de grãos no híbrido simples, quando foi igual ao tipo T4, o tipo de parcela $\mathrm{T} 1$ foi o que

Tabela 3 - Número de repetições (N) e estimativas das médias (M), variâncias (V) e variâncias das médias ( $\left.V_{(M)}\right)$ para rendimento de grãos e número de espigas de dois híbridos de milho para diferentes tipos de parcelas. Santa Maria, 2003.

\begin{tabular}{|c|c|c|c|c|c|c|c|}
\hline \multirow{2}{*}{ Tipo+ } & \multirow{2}{*}{$\mathrm{N}$} & \multicolumn{3}{|c|}{ Rendimento de grãos ( $\mathrm{t} \mathrm{ha}^{-1}$ ) } & \multicolumn{3}{|c|}{$\mathrm{N}^{0}$. de espigas por ha (mil) } \\
\hline & & M & $\mathrm{V}$ & $\mathrm{V}_{(\mathrm{M})}$ & M & $\mathrm{V}$ & $\mathrm{V}_{(\mathrm{M})}$ \\
\hline & & \multicolumn{6}{|c|}{ Híbrido simples = P30F33 } \\
\hline 1 & 12 & 4,602 & 2,172 & 0,425 & 41,875 & 88,494 & 2,715 \\
\hline 2 & 8 & 4,617 & 2,085 & 0,510 & 42,500 & 47,419 & 2,435 \\
\hline 3 & 6 & 4,334 & 1,176 & 0,443 & 41,042 & 42,135 & 2,650 \\
\hline 4 & 6 & 4,426 & 1,157 & 0,439 & 42,187 & 44,180 & 2,713 \\
\hline 5 & 5 & 3,495 & 1,890 & 0,615 & 37,166 & 112,017 & 4,733 \\
\hline 6 & 5 & 3,644 & 1,869 & 0,611 & 37,800 & 104,950 & 4,581 \\
\hline 7 & 8 & 4,765 & 2,492 & 0,558 & 43,437 & 76,228 & 3,087 \\
\hline 8 & 6 & 4,707 & 3,635 & 0,778 & 41,666 & 144,163 & 4,902 \\
\hline \multirow[t]{2}{*}{ Média } & 56 & 4,407 & $2,005^{\mathrm{ns}}$ & 0,189 & 41,325 & $73,888^{\text {ns }}$ & 1,149 \\
\hline & & \multicolumn{6}{|c|}{ Híbrido duplo = AGN 2012} \\
\hline 1 & 12 & 4,596 & 1,352 & 0,336 & 41,979 & 46,979 & 1,967 \\
\hline 2 & 8 & 4,623 & 1,132 & 0,376 & 42,291 & 29,512 & 1,921 \\
\hline 3 & 6 & 4,609 & 0,801 & 0,365 & 43,125 & 33,594 & 2,366 \\
\hline 4 & 6 & 4,306 & 0,855 & 0,377 & 41,250 & 31,250 & 2,282 \\
\hline 5 & 5 & 4,380 & 1,940 & 0,623 & 40,333 & 54,722 & 3,308 \\
\hline 6 & 5 & 4,443 & 1,757 & 0,593 & 41,400 & 47,925 & 3,096 \\
\hline 7 & 8 & 4,610 & 0,962 & 0,347 & 41,406 & 25,642 & 1,790 \\
\hline 8 & 6 & 4,621 & 1,537 & 0,506 & 42,916 & 59,653 & 3,153 \\
\hline Média & 56 & 4,542 & $1,109^{\mathrm{ns}}$ & 0,141 & 41,888 & $35,717^{\mathrm{ns}}$ & 0,799 \\
\hline Média geral & 112 & 4,474 & 1,547 & 0,117 & 41,607 & 54,389 & 0,697 \\
\hline
\end{tabular}

+ = Tipo de parcela conforme a Tabela 1;

ns $=$ variâncias entre tipos de parcelas homogêneas pelo teste de Bartlett, $\alpha=5 \%$.

Ciência Rural, v.35, n.1, jan-fev, 2005. 
Tabela 4 - Número de repetições usadas $(\mathrm{N})$ e estimativas do número de repetições necessárias para diferentes semi-amplitudes do intervalo de confiança em percentagem da média (D), com 5\% de probabilidade de erro, para rendimento de grãos e número de espigas de dois híbridos de milho para diferentes tipos de parcelas. Santa Maria, 2003.

\begin{tabular}{|c|c|c|c|c|c|c|c|}
\hline \multirow{2}{*}{ Tipo+ } & \multirow{2}{*}{$\mathrm{N}$} & \multicolumn{3}{|c|}{ Rendimento de grãos } & \multicolumn{3}{|c|}{$\mathrm{N}^{0}$. de espigas } \\
\hline & & $\mathrm{D}=10 \%$ & $D=20 \%$ & $\mathrm{D}=30 \%$ & $\mathrm{D}=10 \%$ & $D=20 \%$ & $\mathrm{D}=30 \%$ \\
\hline & & \multicolumn{6}{|c|}{ Híbrido simples = P30F33 } \\
\hline $\mathrm{T} 1$ & 12 & 42 & 12 & $8(16)^{*}$ & 22 & $8(16)^{*}$ & 3 \\
\hline $\mathrm{T} 2$ & 8 & 40 & 12 & $7(21)$ & 12 & $4(12)$ & 2 \\
\hline T 3 & 6 & 27 & 8 & $5(20)$ & 12 & $5(20)$ & 2 \\
\hline $\mathrm{T} 4$ & 6 & 25 & 8 & $4(16)$ & 12 & $5(20)$ & 2 \\
\hline T 5 & 5 & 62 & 17 & $9(45)$ & 34 & $10(50)$ & 6 \\
\hline T 6 & 5 & 57 & 16 & $8(40)$ & 31 & $9(45)$ & 5 \\
\hline T 7 & 8 & 45 & 13 & $8(24)$ & 18 & $6(18)$ & 3 \\
\hline $\mathrm{T} 8$ & 6 & 65 & 18 & $9(36)$ & 34 & $10(40)$ & 6 \\
\hline \multirow[t]{2}{*}{ Média } & 56 & 42 & 12 & 7 & 19 & 6 & 4 \\
\hline & & \multicolumn{6}{|c|}{ Híbrido duplo = AGN 2012} \\
\hline $\mathrm{T} 1$ & 12 & 27 & 9 & $5(10)$ & 13 & $5(10)$ & 4 \\
\hline $\mathrm{T} 2$ & 8 & 23 & 8 & $5(15)$ & 9 & $4(12)$ & 3 \\
\hline T 3 & 6 & 26 & 8 & $5(20)$ & 9 & $5(20)$ & 4 \\
\hline $\mathrm{T} 4$ & 6 & 20 & 7 & $4(16)$ & 9 & $5(20)$ & 4 \\
\hline T 5 & 5 & 41 & 12 & 7 ( 35 ) & 15 & $6(30)$ & 3 \\
\hline T 6 & 5 & 37 & 11 & $7(35)$ & 13 & $5(25)$ & 4 \\
\hline T 7 & 8 & 20 & 7 & $4(12)$ & 8 & $4(12)$ & 3 \\
\hline T 8 & 6 & 30 & 9 & $5(20)$ & 15 & $6(24)$ & 4 \\
\hline Média & 56 & 23 & 8 & 5 & 10 & 5 & 4 \\
\hline Média geral & 112 & 32 & 10 & 6 & 15 & 5 & 4 \\
\hline
\end{tabular}

+ = Tipo de parcela conforme a tabela 1

*( ) = Número total de filas por tratamento.

proporcionou o melhor plano experimental nas demais situações. Em geral, planos experimentais que não usam bordadura, em ambos os híbridos, seriam menos onerosos (menor número total de filas por tratamento) sob a mesma precisão.

O híbrido simples exigiu maior número de repetições para o rendimento de grãos que o híbrido duplo, contrariando a seqüência encontrada por MARTIN (2003) ao estudar a precisão de híbridos simples, triplo e duplo. No entanto, tanto num caso como em outro, deve-se considerar, como sendo importante, a existência da diferença de precisão entre híbridos. Além disso, estudos do plano experimental, incluindo todos os híbridos que deverão fazer parte de um experimento, devem contemplar um número diferente de repetições e/ou tamanho de parcela e/ ou uso de bordaduras para que todos os híbridos sejam comparados a um mesmo grau de precisão. Como este procedimento é, na prática, muito complicado, poder-se-ia usar o tamanho de parcela com o número de repetições adequado ao híbrido de maior sensibilidade à variação ambiental, sendo que os demais não seriam prejudicados devido ao “excesso” de precisão.

\section{CONCLUSÕES}

A substituição do uso de bordaduras por um maior número de repetições em experimentos de comparação de híbridos de milho não é vantajosa. Oito repetições de parcela de duas filas proporcionam os melhores planos experimentais, tanto para rendimento de grãos quanto para número de espigas para os híbridos simples e duplo. Parcelas de cinco filas, com as três centrais avaliadas, e parcelas de cinco filas, sendo todas avaliadas, proporcionam os piores planos experimentais para rendimento de grãos e número de espigas para híbridos simples e duplos.

Ciência Rural, v.35, n.1, jan-fev, 2005. 


\section{REFERÊNCIAS BIBLIOGRÁFICAS}

CARGNELUTTI FILHO, A. Densidade de plantas como fator para avaliação adequada dos ensaios de competição de cultivares de milho. 2002. 81f. Tese (Doutorado em Agronomia) - Curso de Pós-graduação em Agronomia, Universidade Federal de Santa Maria.

CARGNELUTTI FILHO, A. et al. A precisão experimental relacionada ao uso de bordaduras nas extremidades das fileiras em ensaios de milho. Ciência Rural, Santa Maria, v.33, n.4, p.607-614, 2003.

LOPES, S.J. Avaliação do efeito de diferentes formas de adubação sobre a precisão de ensaios de milho. 1993. 72f. Dissertação (Mestrado em Agronomia) - Curso de Pósgraduação em Agronomia, Universidade Federal de Santa Maria.

LOPES, S.J.; STORCK, L. A precisão experimental para diferentes manejos na cultura do milho. Ciência Rural, Santa Maria, v.25, n.1, p.49-53, 1995.

LÚCIO, A.D.; STORCK, L. O manejo das culturas interfere no erro experimental. Pesquisa Agropecuária Gaúcha, Porto Alegre, v.5, n.2, p.311-316, 1999.

LÚCIO, A.D. et al. Classificação dos experimentos de competição de cultivares quanto a sua precisão. Pesquisa Agropecuária Gaúcha, Porto Alegre, v.5, n.1, p.99-103, 1999.

MARODIM, V.S. Recomendação de cultivares de milho com base na análise de estabilidade fenotípica. 1999. 60f. Dissertação (Mestrado em Agronomia) - Curso de Pósgraduação em Agronomia, Universidade Federal de Santa Maria.

MARQUES, D.G. As pressuposições e a precisão dos ensaios de competição de cultivares de milho no estado do Rio Grande do Sul. 1999. 42f. Dissertação (Mestrado em Agronomia) - Curso de Pós-graduação em Agronomia, Universidade Federal de Santa Maria.

MARTIN, T.N. Contribuição das bases genéticas de milho para o plano experimental. 2003. 89f. Dissertação (Mestrado em Agronomia) - Curso de Pós-graduação em Agronomia, Universidade Federal de Santa Maria.

NASPOLINI FILHO, V. Variabilidade fenotípica e estabilidade em híbridos simples, híbridos duplos, variedades e compostos de milho (Zea mays L.). 1975. 68f. Dissertação (Mestrado em Genética e Melhoramento de Plantas) - Escola Superior de Agricultura "Luiz de Queiroz".

SILVA, P.S.L. et al. Efeitos de bordaduras lateral em experimento de variedades de milho. Revista Ceres, Viçosa, v.42, n.235, p.277-287, 1994

SOUZA, F.R.S. de et al. Estabilidade de cultivares de milho em diferentes épocas e locais de plantio em Minas Gerais. Pesquisa Agropecuária Brasileira, Brasília, v.26, n.6, p.885-892, 1991.

STORCK, L. et al. Experimentação vegetal. Santa Maria: UFSM, 2000. 198p.

VALENTINI, L. et al. Fileiras de bordadura em ensaios de competição entre variedades de feijão. Ciência e Cultura, Viçosa, v.40, n.10, p.1002-1007, 1988. 